\title{
"Counting" by pigeons: Discrimination of the number of biologically relevant sequential events
}

\author{
Rebecca M. Rayburn-Reeves, Holly C. Miller, and Thomas R. Zentall \\ University of Kentucky, Lexington, Kentucky
}

\begin{abstract}
Numerical competence has been studied in animals under a variety of conditions, but only a few experiments have reported animals' ability to detect absolute number. Capaldi and Miller (1988) tested rats' ability to detect absolute number by using biologically important events - the number of reinforced runs followed by a nonreinforced run - and found that the rats ran significantly slower on the nonreinforced run. In the present experiments, we used a similar procedure. Pigeons were given a sequence of trials in which responding on the first three trials ended in reinforcement but responding on the fourth trial did not (RRRN). When the response requirement on each trial was a single peck (Experiment 1), we found no significant increase in latency to peck on the fourth trial. When the response requirement was increased to 10 pecks (Experiment 2), however, the time to complete the peck requirement was significantly longer on the nonreinforced trial than on the reinforced trials. Tests for control by time, number of responses, and amount of food consumed indicated that the pigeons were using primarily the number of reinforcements obtained in each sequence as a cue for nonreinforcement. This procedure represents a sensitive and efficient method for studying numerical competence in animals.
\end{abstract}

The ability to count and to use the number of objects or events as a cue is a quality that adult humans perform routinely and efficiently; however, the degree to which nonverbal organisms have this ability is more controversial. According to Davis and Pérusse (1988), the term counting can be considered a subset of the more general term numerical competence, which they argue encompasses a broader range of numerical capabilities. A variety of methodologies have been used to study numerical competence in animals, each with some success (see Davis \& Pérusse, 1988; Dehaene, 1997; Emmerton, 2001; Gallistel \& Gelman, 1992, 2000, for reviews).

Although nonhuman animals do not share with humans the possession of a verbal language with which to "tag" or enumerate objects, Gelman and Gallistel (1978) have suggested that animals are able to create nonverbal, internal tags (numerons) to identify objects within an array or across time. Animals may be able to tag items in this way to demonstrate a precise representation of small numerosities and an approximate representation of larger numerosities (Feigenson, Dehaene, \& Spelke, 2004). Additionally, research with infants has reported exact representations of small numbers of objects with a limit of three (see Feigenson \& Carey, 2005, for an object-file model to account for this effect). After studying the numerical competence of a number of species, Koehler (1941) concluded that nonhuman animals are capable of representing numerosity in two ways - one requiring a visuospatial capacity for items presented simultaneously, as in an array, and the other allowing them to enumerate events that occur successively over time (Emmerton, 2001). The simplest form of numerical competence involves relative number discriminations.

\section{Relative Number Discriminations: Simultaneous Presentation}

In simultaneous procedures, subjects have typically been presented with two stimulus arrays varying in the number of items in each array. Subjects are trained to respond to the array containing, for example, the larger number (Knorn, 1987; Koehler, 1941; Watanabe, 1998), or they are presented with a single array, and they are asked to make one response if a small number of items was presented and a different response if a large number of items was presented (Emmerton, 1998; Emmerton, Lohmann, \& Niemann, 1997). These relativenumerosity-discrimination experiments typically show that accuracy is a function of both the relative difference between the two numerosities and the magnitude of the numerosities, a property that obeys Weber's law of scalar variability. That is, both human and nonhuman subjects' accuracy at judging the difference between 5 and 10 items is similar to their accuracy at judging the difference between 20 and 40 items (Brannon, 2006; Evans, Beran, Harris, \& Rice, 2009; Feigenson et al., 2004; Gallistel, 1989; Nieder, 2005; Whalen, Gallistel, \& Gelman, 1999). Although much research has been done with the simultaneous procedure, Rilling (1993)

T. R. Zentall, zentall@uky.edu 
suggested that the sequential procedure may be a better analog of human counting.

\section{Relative Number Discriminations: Sequential Presentation}

Relative number discriminations have also been studied using the sequential approach. For example, subjects can be trained to respond in one way to a series of tones (Meck \& Church, 1983, with rats) or light flashes (Alsop \& Honig, 1991; Keen \& Machado, 1999; Machado \& Keen, 2002; Roberts \& Boisvert, 1998; Roberts, Coughlin, \& Roberts, 2000; Roberts \& Mitchell, 1994, with pigeons) and to respond differently to a series that differs in the number of tones or light flashes.

Other research has investigated subjects' ability to use the number of responses that they have made as a discriminative stimulus. For example, Rilling and McDiarmid (1965) found that pigeons could learn to make one response if the center key went off after they had made 35 pecks and a different response if it went off after they had made 50 pecks. This finding was later determined to be based on number and not on the temporal difference between the two pecking bouts (Rilling, 1967). Similarly, Fetterman (1993) trained pigeons to differentiate between two response frequencies and then tested them with probe trials involving intermediate values. He found that the bisection point of the resulting psychometric function was approximately at the geometric mean. This finding is similar to those from studies investigating time-based discriminations (see Meck \& Church, 1983; Gallistel, 1989, for reviews), and it supports the idea that both relative time discriminations and relative number discriminations may share a similar neural mechanism (but see Roberts et al., 2000, for an alternative account).

\section{Absolute Numerosity}

Researchers also have investigated whether animals can judge the absolute number of a series of events. For example, Mechner (1958) trained rats to press the left lever $n$ times before they pressed the right lever to receive reinforcement. Hurwitz (1962) used a similar procedure, except that rats were required to poke their nose in a food tray to signal when they judged that the appropriate number of leverpresses had been made. Platt and Johnson (1971) trained subjects with this procedure using a variety of numerosities $(4,8,12$, and 16) in a within-subjects design. The typical finding was that the most frequent number of responses occurred at or above the required number. Suzuki and Kobayashi (2000) trained rats to enter one box that had a defined ordinal number among an array of boxes and found that subjects would most often enter the box with the same numerical position that was reinforced during training.

Xia, Siemann, and Delius (2000) conducted a more ambitious study that required pigeons to detect an absolute number of events. They trained pigeons to peck a key that displayed one of several possible Arabic numerals the exact number of times that was displayed on the key (up to four numerals in Experiment 1 and up to six in Experiment 2). Results showed that after extensive training (13,000-20,000 trials in Experiment 1; 12,000-19,000 trials in Experiment 2), some of the subjects were able to make the correct number of responses to each numeral with above-chance accuracy. The level of accuracy achieved and the amount of training required, however, suggest that the procedure is not an efficient method for developing control by number.

A similar paradigm using symbols to represent numerosities requires the subject to peck at each stimulus within an array. Pecking the stimulus changes its color or some property of the stimulus (an indicating response). Subjects are then required to choose a symbol that corresponds to the number of objects in the array (Hirai \& Jitsumori, 2009; Xia, Emmerton, Siemann, \& Delius, 2001). These experiments also required extensive training, however, which resulted in a number of subjects being dropped because of their inability to learn. More successful at demonstrating absolute number discriminations have been experiments with primates (Boysen, Berntson, Hannan, \& Cacioppo, 1996; Brannon \& Terrace, 2000) and an African Gray parrot (Pepperberg, 1994), animals that generally evidence greater conceptual ability.

A more efficient way to assess the ability of animals to discriminate the number of events experienced may be to have them experience a series of salient biologically important events. For example, Seligman and Meyer (1970) investigated the suppression of leverpressing by rats. After rats were reliably leverpressing on a variable-interval schedule for food, exactly three shocks were administered at unpredictable times during the session. The introduction of shocks produced suppression in responding. Once the rats had had some experience with this procedure, however, they began responding at a higher rate after the third (last) shock had been administered.

In a similar vein, Capaldi and Miller (1988) assessed the ability of rats to discriminate the number of appetitive events experienced with sequentially rewarded (R) and nonrewarded $(\mathrm{N})$ alley runs. Each day, the rats were given one exposure to two sequences (RRRN and NRRRN) in random order. After some training, the rats began to show significantly slower running speed on the terminal nonreinforced trial than on the earlier trials, suggesting that the rats were using the number of reinforced runs as a cue for when the nonreinforced run would occur.

Although much of the research on numerical competence in animals has used pigeons as subjects, most of it has involved relative number discriminations. The purpose of the present experiments was to ask whether pigeons would show evidence of numerical competence when the events to be enumerated were biologically important events. In the present research, pigeons were presented with four trial sequences in which reinforcement for responding was presented on the first three trials but not the fourth. We asked whether pigeons would show evidence of number discrimination in the form of increased latency to respond on the fourth trial of the sequence. In Experiment 1, the response requirement was a single peck. 


\section{EXPERIMENT 1}

\section{Method}

\section{Subjects}

Eight White Carneaux pigeons (Columbia livia) ranging in age from 2 to 12 years served as subjects. All subjects had experience in previous, unrelated studies. Throughout the experiment, the pigeons were maintained at $85 \%$ of their free-feeding weight. They were housed individually in wire cages, with free access to water and grit, in a colony room that was maintained on a 12-h/12-h light/dark cycle. The pigeons were maintained in accordance with a protocol approved by the Institutional Animal Care and Use Committee at the University of Kentucky.

\section{Apparatus}

The experiment was conducted in a BRS/LVE (Laurel, MD) sound-attenuating standard operant test chamber measuring $34 \mathrm{~cm}$ high, $30 \mathrm{~cm}$ from the response panel to the back wall, and $35 \mathrm{~cm}$ across the response panel. Three circular response keys $(2.54 \mathrm{~cm}$ in diameter) were aligned horizontally on the response panel and were separated from each other by $6 \mathrm{~cm}$, but only the center response key was used in these experiments. The bottom edge of the response keys was $24 \mathrm{~cm}$ from the wire-mesh floor. A 12-stimulus in-line projector (Industrial Electronics Engineering, Van Nuys, CA) with 28-V, 0.1-A lamps (GE 1820) that projected a white light (no filter) was mounted behind the center response key. Mixed-grain reinforcement (Purina Pro Grains: a mixture of corn, wheat, peas, kafir, and vetch) was provided from a raised and illuminated grain feeder that was located behind a horizontally centered $5.1 \times 5.7 \mathrm{~cm}$ aperture located vertically midway between the response keys and the floor of the chamber. Reinforcement consisted of $1.5-\mathrm{sec}$ access to the mixed grain. A blue houselight, which provided 1.5 -sec of illumination for the outcome on nonreinforced trials, was mounted $4.5 \mathrm{~cm}$ above the center response key. A second, white houselight, which provided general illumination between sequences, was located in a central position on the ceiling of the chamber. The experiment was controlled by a microcomputer and interface that were located in an adjacent room.

\section{Procedure}

Training. At the start of each experimental session, the center key was illuminated white. A single response to the center key turned the keylight off and resulted in 1.5-sec access to reinforcement. Immediately after reinforcement, the white center keylight was again illuminated, indicating the start of the next trial. Three trials proceeded in this way. On the fourth trial, a peck resulted in the illumination of the blue houselight for $1.5 \mathrm{sec}$. On the first three trials of a sequence, if a subject failed to make a response within $30 \mathrm{sec}$, the trial was terminated with reinforcement. On the fourth trial of a sequence, if a subject failed to make a response within $30 \mathrm{sec}$, the trial was terminated with the blue houselight. Each session consisted of 10 four-trial sequences. To ensure distinctiveness of the sequences, they were separated by a $120-\mathrm{sec}$ intersequence interval, during which the white houselight was illuminated. All subjects were trained for 600 sequences. The latency to make a single response on the center key was the dependent measure.

\section{Results}

The latency to make a single peck as a function of trial number, averaged over the last 10 training sessions, declined slightly from Trial 1 to Trial 2 and from Trial 2 to Trial 3, but it did not increase on Trial 4, the nonreinforced trial. The data from Experiment 1 are presented in the gray bars of Figure 1. A one-way repeated measures ANOVA was conducted on the latency scores pooled over the last 10 training sessions, as a function of trial number. The analysis indicated that the effect of trial number was not

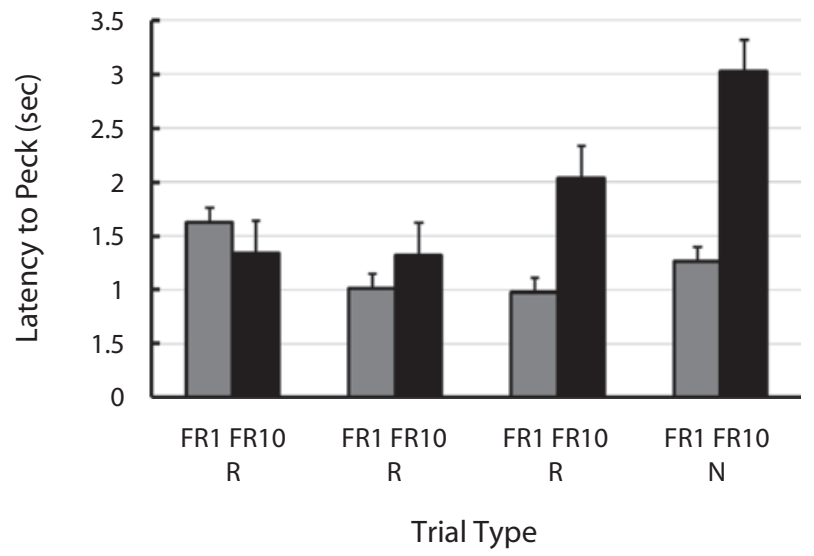

Figure 1. Experiments 1 and 2, training. Mean latency to the 1st peck as a function of trial number for Sessions 51-60. In Experiment 1 (gray bars), the 1st peck (FR1) was reinforced on the first three trials of each sequence but not on the fourth trial. In Experiment 2 (black bars), the 10th peck (FR10) was reinforced on the first three trials of each sequence but not on the fourth trial.

significant $(F<1)$. Furthermore, a planned comparison indicated that there was not a significant difference in latency between the third (reinforced) trial and the fourth (nonreinforced) trial $(F<1)$.

\section{Discussion}

The results of Experiment 1 indicate that when pigeons were required to peck only once for each of the three consecutive reinforcements, they did not respond more slowly on the fourth trial, in which the response was not reinforced. If the number of reinforced responses controlled the latency to respond on the last trial, the pigeons' latency to respond should have been longer on the fourth trial. In Experiment 1, we required only a single peck per trial to minimize the duration of the sequence and thus, we thought, reduce the memory requirement (the time from the first trial to the fourth trial); however, the failure to obtain reinforcement on the fourth trial did not appear to inhibit pecking. Therefore, either the pigeons were not able to use the number of reinforcements as a cue for nonreinforcement, or the minimal cost of making a single peck on the fourth trial was insufficient to encourage the pigeons to discriminate the fourth (nonreinforced) trial from the others. It is possible that requiring additional responses to the key on each trial might incur a greater penalty for short latency responses on nonreinforced trials; thus, the purpose of the second experiment was to determine whether increasing the number of pecks to obtain reinforcement would make pigeons more sensitive to nonreinforcement on the fourth trial.

\section{EXPERIMENT 2}

\section{Method}

Subjects

Ten White Carneaux pigeons (Columbia livia) similar to those used in Experiment 1 were used as subjects. They were housed and maintained similarly as well. 


\section{Apparatus}

The apparatus used in Experiment 2 was the same as that used in Experiment 1.

\section{Procedure}

Pretraining. Each subject was trained to peck the white center response key for reinforcement, starting with 1 peck and increasing gradually to 10 pecks.

Training. The training procedure was similar to that in Experiment 1 , with the exception that 10 pecks were required to the white center key on each trial. Each pigeon received 10 four-trial sequences per session, for a total of 900 sequences.

Test 1. To determine whether the pigeons were timing from the beginning of the sequence as a source of behavioral control - and to distinguish among number of trials, number of pecking bouts, and number of reinforcements as the basis for nonreinforcementthe pigeons were tested with a modified version of the training sequence in which a nonreinforced trial was added at the beginning of the training sequence (NRRRN). Each pigeon received 5 training sequences (RRRN) and 5 test sequences (NRRRN), randomly intermixed, during each test session. There were 20 test sessions. Each subject was then given 10 additional training sessions involving only RRRN sequences, in order to reestablish the training baseline.

Test 2. To determine whether the pigeons were using the amount of food eaten over the first three trials in a sequence as the basis for determining the start of the fourth trial, the original sequence that was presented during training was modified so that reinforcement time was doubled (to $3 \mathrm{sec}$ ) on the first three trials of each sequence. As with the procedure used in Test 1 , the doubled reinforcement time and the original reinforcement time sequences were each randomly presented for 5 of the 10 sequences per session. Test 2 was continued for 20 sessions. Each subject was then given 10 additional training sessions involving only RRRN sequences, in order to reestablish the training baseline.

Test 3. To determine whether pigeons were using the time from the start of the sequence as the basis for determining the start of the fourth trial, the original sequence during training was again modified to include a dark delay of $1.5 \mathrm{sec}$ between reinforcement and the start of the next trial. As with the procedures used in Tests 1 and 2, the modified delay sequences and the original training sequences were each presented randomly for 5 of the 10 sequences per session. Subjects were tested for 20 sessions.

\section{Results}

\section{Training}

To compare the results from Experiment 1 with those of Experiment 2, we examined the latency to make the first peck as a function of trial number for Sessions 5160. This comparison indicated that in Experiment 2 there was a small increase in latency from Trial 1 to Trial 2, a somewhat larger increase in latency from Trial 2 to Trial 3, and a somewhat larger increase in latency from Trial 3 to Trial 4. The latency on Trial 4 represented an increase in latency of $32 \%$ relative to the latency on Trial 3 . The firstpeck latency data as a function of trial number appear as black bars in Figure 1. A repeated measures ANOVA performed on the first-peck latency data as a function of trial number indicated that the effect of trial number was statistically significant $[F(3,27)=3.32, p=.032]$. Similarly, when the mean latencies were pooled over the first three trials and compared with the latency on the fourth trial using a paired-samples $t$ test, the difference was not significant $[t(9)=1.89, p=.092]$. A one-way ANOVA was conducted on the three reinforced trials, and the ef-

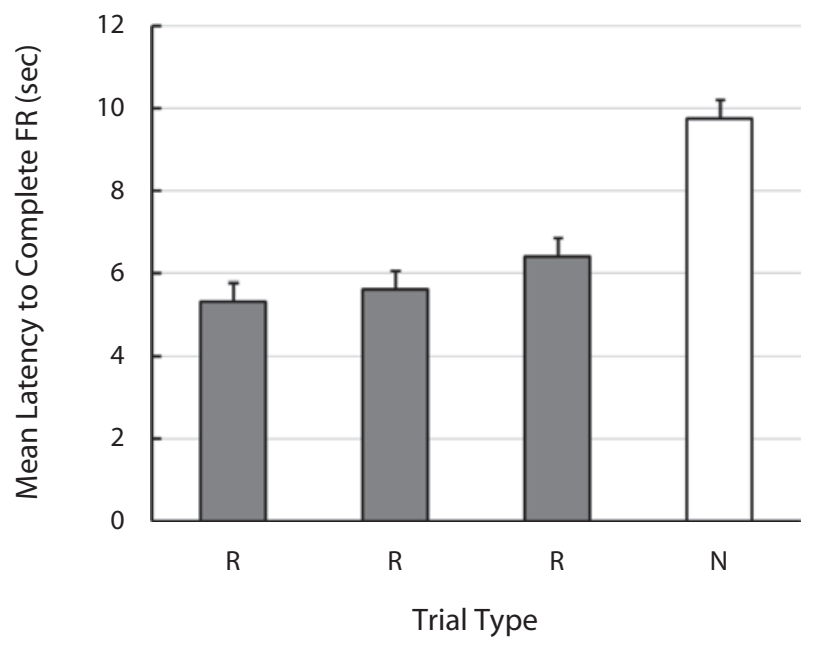

Figure 2. Experiment 2, training. Mean latency to complete the 10-peck (FR10) requirement as a function of trial number for Training Sessions 81-90.

fect was not significant $[F(2,18)=1.61, p=.23]$. Finally, there was also a significant difference in latency between Trial 3 and Trial $4[t(9)=2.66, p=.026]$.

The latency to complete the fixed-ratio requirement, when pooled over Sessions 81-90, showed a significant effect of trial number. The latency on Trial 3 represented an increase in latency of $5.5 \%$ relative to the latency on Trial 2, whereas the latency on Trial 4 represented an increase in latency of $30.8 \%$ relative to the latency on Trial 3. The mean latency scores as a function of trial number are presented in Figure 2. A repeated measures ANOVA performed on the latency scores as a function of trial number indicated that the effect of trial number was statistically significant $[F(3,27)=6.29, p=.002]$. When the mean latencies were pooled over the first three trials and compared with the latency on the fourth trial using a paired-samples $t$ test, the difference was also significant $[t(9)=2.62, p=.028]$. A one-way ANOVA was also conducted on the latencies for the three reinforced trials, and the effect was not significant $[F(2,18)=2.82$, $p=.086]$. Finally, the difference in mean latency scores between Trial 3 and Trial 4 was statistically significant $[t(9)=2.77, p=.022]$.

Because not all of the pigeons in Experiment 2 showed a reliable increase in latency to complete the peck requirement from Trial 3 to Trial 4, a paired-samples $t$ test was conducted on each subject's data for Trials 3 and 4 pooled over Sessions 81-90. For 6 out of the 10 pigeons, the increase in latency was statistically significant. For this reason, only those 6 subjects were tested in subsequent conditions for the source of the difference.

\section{Test 1: Testing Sequence}

The purpose of Test 1, in which a nonreinforced trial (N) was added to the beginning of the original training sequence, was to determine if the increase in latency on Trial 4 resulted from timing from the beginning of the 


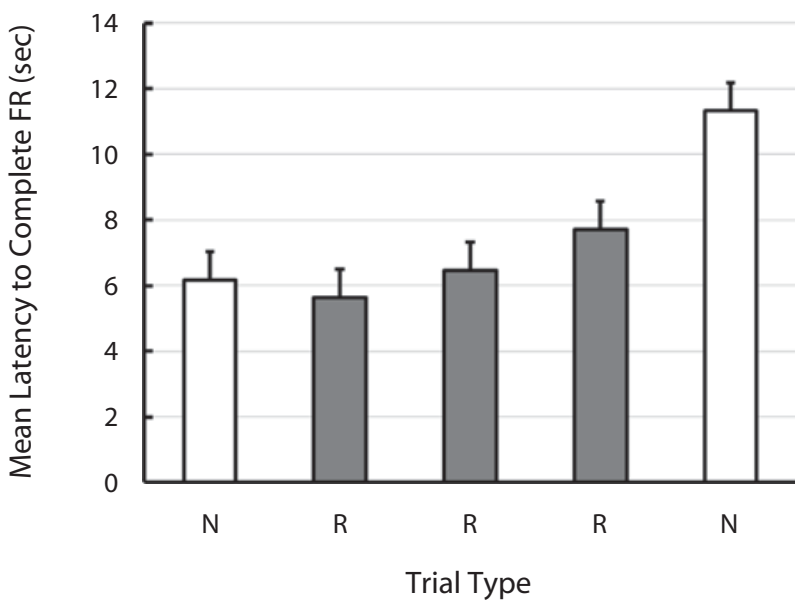

Figure 3. Experiment 2, Test 1. Mean latency to complete the 10-peck (FR10) requirement as a function of trial type for testing sequences averaged across subjects and the 20 testing sessions. Testing sequences had an additional no-food trial $(N)$ at the beginning of the sequence.

sequence, the number of trials experienced, the number of prior pecking bouts, or the number of reinforcements. On Test 1 trials, there was only a small increase (16.2\%) in latency between Trials 3 and 4 (the second and third reinforced trials), whereas there was a large increase $(32.0 \%)$ in latency between Trials 4 and 5 (the last reinforced trial and the following nonreinforced trial). The data from Test 1 appear in Figure 3. A repeated measures ANOVA on the 10-peck latency data as a function of trial number indicated that the effect of trial number was statistically significant $[F(4,20)=15.35, p<.001]$. Again, when the mean latencies were pooled over the first three reinforced trials and compared with the latency on the fifth trial using

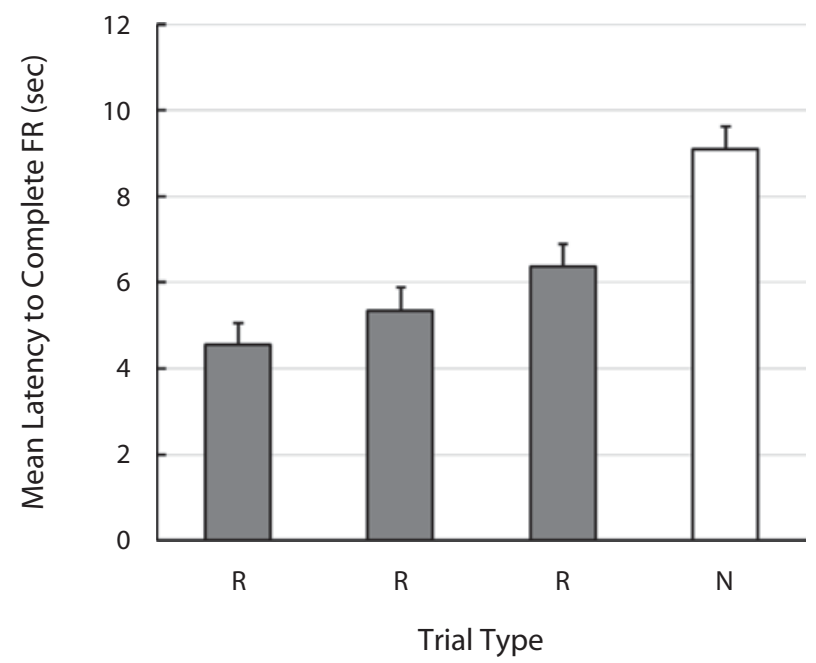

Figure 4. Experiment 2, Test 2. Mean latency to complete the 10-peck (FR10) requirement as a function of trial type for the testing sequences averaged across subjects and the 20 testing sessions. Testing sequences had 3 sec of reinforcement. a paired-samples $t$ test, the difference was also significant $[t(5)=4.27, p=.008]$. A one-way ANOVA conducted on the data from the three reinforced trials indicated that the effect was significant $[F(2,10)=6.48, p=.016]$; however, a paired-samples $t$ test conducted on second and third reinforced trials (Trials 3 and 4) indicated that the effect was not quite significant $[t(5)=2.56, p=.051]$. Finally, there was once again a significant difference in latency between the last reinforced trial (Trial 4) and the final nonreinforced trial (Trial 5) $[t(5)=3.50, p=.017]$. Latencies on the training sequences from Test 1 showed results similar to those found during training. There was a significant difference in latency between the last reinforced trial (Trial 3) and the nonreinforced trial (Trial 4) $[t(5)=3.52, p=.017]$.

\section{Test 2: Testing Sequence}

In Test 2, the reinforcement duration was doubled on each reinforced trial to determine whether the pigeons were using the amount of food eaten during each sequence as the basis for estimating the start of the fourth trial. The data from Test 2 appear in Figure 4. On Test 2 sequences, there was again a small increase $(15.8 \%)$ in latency between Trials 2 and 3, whereas there was a large increase $(30.0 \%)$ in latency between Trials 3 and 4 (the last reinforced trial and the following nonreinforced trial). For the 6 birds that initially showed an increase in latency on Trial 4 during baseline training, the mean latency to complete the 10 -peck requirement varied significantly as a function of trial number $[F(3,15)=9.62, p=.001]$. Again, when the mean latencies were pooled over the first three trials and were compared with the latency on the fourth trial using a paired-samples $t$ test, the difference was also significant $[t(5)=3.73, p=.014]$. A one-way ANOVA was conducted for the three reinforced trials, and a significant effect was found $[F(2,10)=5.06, p=.03]$. Finally, the latency to complete Trial 3 (the last reinforced trial) was significantly shorter than the latency to complete Trial 4 (the nonreinforced trial) $[t(5)=3.03, p=$ .029]. A paired-samples $t$ test for the training sequences from Test 2 showed a nonsignificant difference between the last reinforced trial (Trial 3) and the nonreinforced trial (Trial 4) $[t(5)=2.073, p=.093]$.

\section{Test 3: Testing Sequence}

As a further test of the possibility that the pigeons were timing from the start of the sequence to the start of the fourth trial, sequences from original training were randomly presented during Test 3 with testing sequences in which a dark delay of $1.5 \mathrm{sec}$ was introduced between trials. On Test 3 sequences, there was a moderate increase $(20.66 \%)$ in latency between Trials 2 and 3, whereas there was a substantially larger increase $(36.02 \%)$ in latency between Trials 3 and 4 . The data from Test 3 appear in Figure 5. Data pooled over the 20 sessions of Test 3 indicated that there was a significant effect of trial number $[F(3,15)=6.18, p=.006]$. As with the previous tests, mean latencies were pooled over the first three trials 


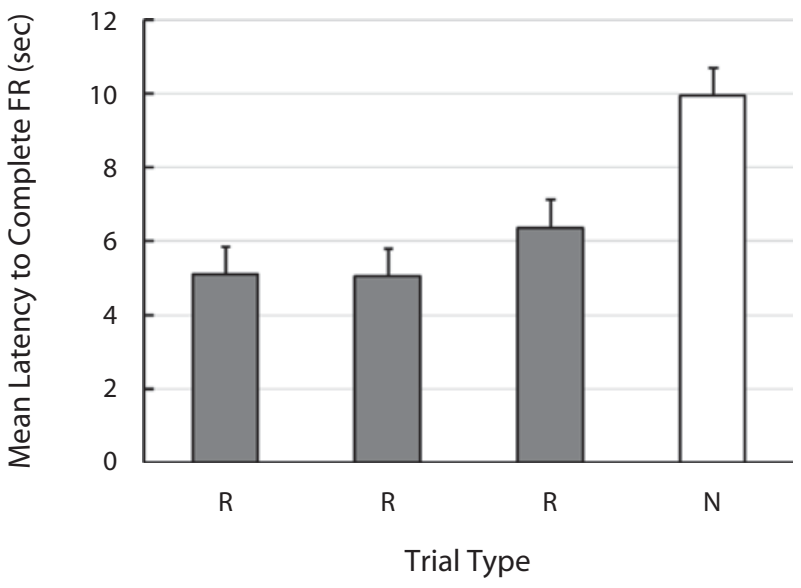

Figure 5. Experiment 2, Test 3. Mean latency to complete the 10-peck (FR10) requirement as a function of trial type for the testing sequences averaged across subjects and the 20 testing sessions. Testing sequences had 1.5 -sec delays between trials.

and compared with the latency on the fourth trial using a paired-samples $t$ test, and the difference was marginally significant $[t(5)=2.56, p=.051]$. When we compared the mean latencies across the three reinforced trials using a one-way ANOVA, the effect was not significant $[F(2,10)=1.44, p=.282]$. Finally, there was a significant difference in latency between the last reinforced trial and the nonreinforced trial $[t(5)=3.31, p=.021]$. The training sequences from Test 3 showed a significant difference between the last reinforced trial (Trial 3) and the nonreinforced trial (Trial 4) $[t(5)=9.39, p=.032]$.

\section{Discussion}

The results of Experiment 2 indicate that when pigeons were given experience with RRRN sequences of trials with 10 pecks required on each trial, they showed a significant difference in the time to complete the pecking requirement on R trials versus $\mathrm{N}$ trials. Furthermore, the results of the three tests indicate that the pigeons were not using the elapsed time from the start of a sequence as the basis for the discrimination - nor were they using the number of pecking bouts or the amount of food eaten.

For the first test, we added a nonreinforced trial at the beginning of the sequence (NRRRN) and found a large increase in latency after the fourth trial (the third reinforced trial) rather than after the third trial (the second reinforced trial). For the second test, we asked whether the amount of food consumed might have been a cue to nonreinforcement, but once again the pigeons showed an increase in latency after the third reinforced trial rather than after the second reinforced trial, after which the pigeons would have consumed as much food as after three reinforced trials during training. For the third test, we asked whether introducing a delay between trials would affect their ability to discriminate when nonreinforcement would occur during the trial; again, pigeons showed an increase in latency to respond on the nonreinforced trial as opposed to on the third reinforced trial. The results suggest that the number of reinforcements was the controlling variable in the increase in latency to complete the 10-peck requirement on the final, nonreinforced trial.

\section{GENERAL DISCUSSION}

The results of Experiment 2 produce a pattern of data suggesting that pigeons have the ability to predict a trial with nonreinforcement following three trials with reinforcement. In Experiment 1, with a single peck requirement, the pigeons showed no evidence of numerical competence in the form of an increase in response latency on the fourth (nonreinforced) trial of the sequence; however, when the response requirement was increased to 10 pecks in Experiment 2, a significant increase in response latency on the fourth trial was found. It appears that the low cost and immediacy of reinforcement that were associated with making a single peck did not encourage the pigeons to delay responding on the fourth trial of a sequence. Interestingly, if time had been a controlling factor in cuing nonreinforcement in Experiment 2, the pigeons should have been able to time the duration of the sequence more easily in Experiment 1, because the time from the start of the sequence to the fourth trial would have been considerably shorter than that in Experiment 2.

The results of Experiment 2 provide evidence that pigeons are capable of using the number of reinforcements obtained in a sequence as a discriminative cue for nonreinforcement. Furthermore, the results of Experiment 2 demonstrate that the increase in latency on the final (nonreinforced) trial was attributable largely to the number of reinforcers rather than to the duration of the sequence, the number of 10-peck responses, or the amount of food consumed.

It should be noted that in Tests 1 and 2 we did find a significant difference in latency among the three reinforced trials, which suggests that timing may have played a role in responding during these tests. We did not see a similar effect in training, however-or, importantly, in Test 3, in which we specifically controlled for timing during the sequence by inserting a delay between trials. The fact that we did not see a difference in training when both number and time could have been used to anticipate nonreinforcement suggests that number was the controlling variable. Additionally, if subjects were relying on the time to nonreinforcement from the start of the sequence, then the procedure used in Test 3 should have shown it. Although timing may have played a small role in Tests 1 and 2, it did not do so in training or in Test 3 and thus cannot account for the results found in Experiment 2.

The value of the present procedure is that it provides the animal with a sequence of salient, biologically important events (reinforcement followed by the absence of reinforcement) that are relatively easy to learn. Although much of the past research on numerical competence in animals has been conducted with pigeons, almost all of it has involved relative number discriminations. The present research demonstrates that pigeons can discriminate absolute number as well. 
The present research asked a fundamental question concerning the numerical competence of pigeons; however, variations of this procedure could be used to ask whether pigeons can show a similar ability to predict the occurrence of nonreinforcement when the reinforced trials do not directly follow one another. For example, one could ask whether pigeons would show significantly longer latencies on the last trial if they were trained with mixed sequences such as RNRRN, RNRNRN, or perhaps even RNRNNRN.

Other procedures could be used to determine whether pigeons are able to enumerate two different quantities depending on a conditional cue. For example, Burns and Sanders (1987) asked whether rats can be cued independently to enumerate a different number of reinforcements depending on the context of the series. They trained rats on an alternating series of RRN and NRRN under one level of illumination, and RRRN and NRRRN under a different level of illumination, and they found that in both conditions the subjects learned to run more slowly on the last trial. One could thus ask whether pigeons can learn that there will be a nonreinforced trial after three reinforcements in a series with the houselight on, and a nonreinforced trial after two trials in a series with the houselight off.

One could also ask whether pigeons can discriminate the number of reinforcers of a particular type from the total number of reinforcers. Capaldi, Miller, and Alptekin (1989) showed that rats can use the number and type of food that they find in the goal box to signal the occurrence of nonreinforcement. They trained rats with trials in which one type of food $\left(\mathrm{F}_{1}\right)$ was presented on some trials $\left(\mathrm{F}_{1} \mathrm{~F}_{1} \mathrm{~N}\right.$ or $\left.\mathrm{NF}_{1} \mathrm{~F}_{1} \mathrm{~N}\right)$ and a different type of food $\left(\mathrm{F}_{2}\right)$ was presented on other trials $\left(\mathrm{F}_{2} \mathrm{~F}_{2} \mathrm{~F}_{2} \mathrm{~N}\right.$ or $\left.\mathrm{NF}_{2} \mathrm{~F}_{2} \mathrm{~F}_{2} \mathrm{~N}\right)$, and they found that the rats ran slower on the last trial of each series. The rats were thus able to base their judgment of the last reinforcement on the kind of food they found. If it was $F_{1}$, there would be only two reinforcements, but if it was $\mathrm{F}_{2}$, there would be three.

Although a procedure involving the enumeration of salient, biologically important events is particularly useful to study numerical competence in nonverbal animals, because of the salience of the events it may also be useful in teaching counting to developmentally delayed children and children with learning disabilities whether they have verbal competence or not.

\section{AUTHOR NOTE}

Correspondence concerning this article should be addressed to T. R. Zentall, Department of Psychology, University of Kentucky, Lexington, KY 40506-0044 (e-mail: zentall@uky.edu).

\section{REFERENCES}

Alsop, B., \& Honig, W. K. (1991). Sequential stimuli and relative numerosity discriminations in pigeons. Journal of Experimental Psychology: Animal Behavior Processes, 17, 386-395.

Boysen, S. T., Berntson, G. G., Hannan, M. B., \& Cacioppo, J. T. (1996). Quantity-based interference and symbolic representations in chimpanzees (Pan troglodytes). Journal of Experimental Psychology: Animal Behavior Processes, 22, 76-86.
BranNon, E. M. (2006). The representation of numerical magnitude. Current Opinion in Neurobiology, 16, 222-229.

Brannon, E. M., \& Terrace, H. S. (2000). Representation of the numerosities 1-9 by rhesus macaques (Macaca mulatta). Journal of Experimental Psychology: Animal Behavior Processes, 26, 31-49.

Burns, R. A., \& Sanders, R. E. (1987). Concurrent counting of two and three events in a serial anticipation paradigm. Bulletin of the Psychonomic Society, 25, 479-481.

CAPAldi, E. J., \& Miller, D. J. (1988). Counting in rats: Its functional significance and the independent cognitive processes that constitute it. Journal of Experimental Psychology: Animal Behavior Processes, 14, 3-17.

Capaldi, E. J., Miller, D. J., \& Alptekin, S. (1989). A conditional numerical discrimination based on qualitatively different reinforcers. Learning \& Motivation, 20, 48-59.

Davis, H., \& Pérusse, R. (1988). Numerical competence in animals: Definitional issues, current evidence, and a new research agenda. $B e$ havioral \& Brain Sciences, 11, 561-615.

Dehaene, S. (1997). The number sense: How the mind creates mathematics. New York: Oxford University Press.

Emmerton, J. (1998). Numerosity differences and effects of stimulus density on pigeons' discrimination performance. Animal Learning \& Behavior, 26, 243-256.

EMmerton, J. (2001). Birds' judgments of number and quantity. In R. G. Cook (Ed.), Avian visual cognition. Retrieved from www.pigeon .psy.tufts.edu/avc/emmerton

Emmerton, J., Lohmann, A., \& Niemann, J. (1997). Pigeons' serial ordering of numerosity with visual arrays. Animal Learning \& Behavior, 25, 234-244.

Evans, T. A., Beran, M. J., Harris, E. H., \& Rice, D. F. (2009). Quantity judgments of sequentially presented food items by capuchin monkeys (Cebus apella). Animal Cognition, 12, 97-105.

FEIGENSON, L., \& CAREY, S. (2005). On the limits of infants' quantification of small object arrays. Cognition, 97, 295-313.

Feigenson, L., Dehaene, S., \& Spelke, E. (2004). Core systems of number. Trends in Cognitive Sciences, 8, 307-314.

Fetterman, J. G. (1993). Numerosity discrimination: Both time and number matter. Journal of Experimental Psychology: Animal Behavior Processes, 19, 149-164.

Gallistel, C. R. (1989). Animal cognition: The representation of space, time and number. Annual Review of Psychology, 40, 155-189.

Gallistel, C. R., \& Gelman, R. (1992). Preverbal and verbal counting and computation. Cognition, 44, 43-74.

Gallistel, C. R., \& Gelman, R. (2000). Non-verbal numerical cognition: From reals to integers. Trends in Cognitive Sciences, 4, 59-65.

Gelman, R., \& Gallistel, C. R. (1978). The child's understanding of number. Cambridge, MA: Harvard University Press.

HiraI, S., \& Jitsumori, M. (2009). Counting absolute numbers of items, from 1 to 8, in pigeons. Learning \& Behavior, 37, 365-379.

Hurwitz, H. M. B. (1962). Some properties of behaviour under fixedratio and counting schedules. British Journal of Psychology, 53, 167173.

Keen, R., \& Machado, A. (1999). How pigeons discriminate the relative frequency of events. Journal of the Experimental Analysis of Behavior, 72, 151-175.

KNORN, H.-J. (1987). Visuelle Diskriminationsleistung von Tauben und Menschen beim simultanen Punktmengenvergleich [Visual discrimination performance of pigeons and humans when simultaneously comparing dot quantities]. Unpublished Diplomarbeit, Ruhr University Bochum, Bochum, Germany.

KoeHLER, O. (1941). Vom Erlernen unbenannter Anzahlen bei Vögeln [On the learning of unnamed numerosities by birds.] Naturwissenschaften, 29, 201-218.

Machado A., \& Keen, R. (2002). Relative numerosity discrimination in the pigeon: Further tests of the linear-exponential-ratio model. $B e-$ havioural Processes, 57, 131-148.

Mechner, F. (1958). Probability relations within response sequences under ratio reinforcement. Journal of the Experimental Analysis of Behavior, 1, 109-121.

MecK, W. H., \& ChURCH, R. M. (1983). A mode control model of counting and timing processes. Journal of Experimental Psychology: Animal Behavior Processes, 9, 320-334. 
NIEDER, A. (2005). Counting on neurons: The neurobiology of numerical competence. Nature Reviews Neuroscience, 6, 177-190.

Pepperberg, I. M. (1994). Numerical competence in an African Gray Parrot (Psittacus erithacus). Journal of Comparative Psychology, 108, 36-44.

Platt, J. R., \& Johnson, D. M. (1971). Localization of position within a homogenous behavior chain: Effects of error contingencies. Learning \& Motivation, 2, 386-414.

RiLLING, M. (1967). Number of responses as a stimulus in fixed interval and fixed ratio schedules. Journal of Comparative \& Physiological Psychology, 63, 60-65.

RILLING, M. (1993). Invisible counting animals: A history of contributions from comparative psychology, ethology, and learning theory. In S. T. Boysen \& E. J. Capaldi (Eds.), The development of numerical competence: Animal and human models (pp. 3-37). Hillsdale, NJ: Erlbaum.

Rilling, M., \& McDiarmid, C. (1965). Signal detection in fixed-ratio schedules. Science, 148, 526-527.

Roberts, W. A., \& BoIsverT, M. J. (1998). Using the peak procedure to measure timing and counting processes in pigeons. Journal of Experimental Psychology: Animal Behavior Processes, 24, 416-430.

Roberts, W. A., Coughlin, R., \& RoberTs, S. (2000). Pigeons flexibly time or count on cue. Psychological Science, 11, 218-222.
Roberts, W. A., \& Mitchell, S. (1994). Can a pigeon simultaneously process temporal and numerical information? Journal of Experimental Psychology: Animal Behavior Processes, 20, 66-78.

Seligman, M. E. P., \& Meyer, B. (1970). Chronic fear and ulceration in rats as a function of unpredictability of safety. Journal of Comparative \& Physiological Psychology, 73, 202-207.

Suzuki, K., \& Kobayashi, T. (2000). Numerical competence in rats (Rattus norvegicus): Davis and Bradford (1986) extended. Journal of Comparative Psychology, 114, 73-85.

Watanabe, S. (1998). Discrimination of "four" and "two" by pigeons. Psychological Record, 48, 383-391.

Whalen, J., Gallistel, C. R., \& Gelman, R. (1999). Nonverbal counting in humans: The psychophysics of number representation. Psychological Science, 10, 130-137.

Xia, L., Emmerton, J., Siemann, M., \& Delius, J. D. (2001). Pigeons (Columba livia) learn to link numerosities with symbols. Journal of Comparative Psychology, 115, 83-91.

Xia, L., Siemann, M., \& Delius, J. D. (2000). Matching of numerical symbols with number of responses by pigeons. Animal Cognition, 3, 35-43.

(Manuscript received September 16, 2009; revision accepted for publication November 30, 2009.) 